\title{
BMJ Open Prevalence of potentially inappropriate medications at admission and discharge among hospitalised elderly patients with acute medical illness at a single centre in Japan: a retrospective cross- sectional study
}

Junpei Komagamine

To cite: Komagamine J. Prevalence of potentially inappropriate medications at admission and discharge among hospitalised elderly patients with acute medical illness at a single centre in Japan: a retrospective cross-sectional study. BMJ Open 2018;8:e021152. doi:10.1136/ bmjopen-2017-021152

- Prepublication history and additional material for this paper are available online. To view these files, please visit the journal online (http://dx.doi. org/10.1136/bmjopen-2017021152).

Received 13 December 2017 Revised 26 April 2018 Accepted 15 June 2018

A Check for updates

(C) Author(s) (or their employer(s)) 2018. Re-use permitted under CC BY-NC. No commercial re-use. See rights and permissions. Published by BMJ.

Department of Internal Medicine, National Hospital Organisation Tochigi Medical Centre, Utsunomiya, Japan

Correspondence to Dr Junpei Komagamine; junpei0919@yahoo.co.jp

\section{ABSTRACT}

Objective To determine the prevalence of potentially inappropriate medications (PIMs) at admission and discharge among hospitalised elderly patients with acute medical illness in Japan.

Design A retrospective single-centre cross-sectional study.

Participants Hospitalised patients aged 65 years or older admitted for pneumonia, heart failure, ischaemic stroke, acute coronary syndrome, chronic obstructive pulmonary disease or asthma, gastrointestinal bleeding, urinary tract infection or epilepsy from September 2014 to June 2016 who were still alive at discharge.

Main outcome measures The primary outcome was the proportion of patients taking at least one PIM at admission and discharge. PIMs were defined based on the 2015 American Geriatric Society Beers Criteria. Temporal changes in the proportion of patients taking at least one PIM from admission to discharge were also evaluated. Results During the study period, 689 eligible patients were identified. The median patient age was 82.0 years (IQR 76.0-88.0), 348 (50.5\%) were men and the median number of medications at admission was 5.0 (IQR 3.0-8.0). The proportions of patients taking any PIMs at admission and discharge were $47.9 \%(95 \% \mathrm{Cl}$ $44.2 \%$ to $51.6 \%$ ) and $25.1 \%$ (95\% Cl $21.9 \%$ to $28.4 \%$ ), respectively. The proportion of patients taking any PIMs was significantly lower at discharge than at admission (reduction rate $0.48,95 \%, \mathrm{Cl} 0.41$ to 0.53 ).

Conclusions A substantial proportion of hospitalised elderly patients with acute medical illness took PIMs at admission and discharge. These findings should be confirmed at other hospitals in Japan.

\section{INTRODUCTION}

Polypharmacy is a common problem among elderly patients due to the high prevalence of multiple morbidities, ${ }^{12}$ and it is associated with the use of potentially inappropriate medications (PIMs). ${ }^{4}$ PIMs have been defined as medications that have an unfavourable
Strengths and limitations of this study

- This is the first study to evaluate the temporal change in the prevalence of potentially inappropriate medication (PIM) use from admission to discharge among hospitalised elderly patients with acute medical illness in Japan.

- This study was conducted at a single hospital in Japan with a small sample of patients.

- The prevalence of PIM use after discharge was not evaluated.

balance between the benefit and harm they cause for many elderly adults. ${ }^{5}$ Several geriatric experts have proposed medication lists regarding PIMs that should be avoided as much as possible for elderly adults. ${ }^{6-8}$ Although PIMs are associated with a risk of harmful events, ${ }^{9}{ }^{10}$ they are commonly taken by elderly patients, ${ }^{41}$ particularly in acute care settings such as hospitals. ${ }^{12} 13$ Therefore, it is important to monitor the prevalence of PIM use among hospitalised elderly patients with acute illness.

The prevalence of PIM use at admission in hospitalised elderly patients with acute illness in past studies was found to range from $20 \%$ to $70 \% .^{12}{ }^{14-24}$ Furthermore, the prevalence of PIM use is often unchanged or increased at discharge, ${ }^{14-18}$ although some studies have reported that geriatric care unit admission reduced the use of PIMs from admission to discharge among elderly patients with acute medical illness. ${ }^{19-24}$ However, to the knowledge of the author, no studies have been conducted to investigate the prevalence of PIM use at admission and discharge among hospitalised elderly patients in Japan. Thus, the aim of this study was to determine the 
prevalence of PIM use at admission and discharge among this patient population.

\section{METHODS}

\section{Study design and participants}

This was a retrospective cross-sectional study using the database of the National Hospital Organisation Tochigi Medical Centre, and data from September 2014 to June 2016 were collected. The National Hospital Organisation Tochigi Medical Centre is a 350-bed community hospital in the Tochigi Prefecture of Japan. It is one of the two largest acute care hospitals in this area, serving approximately 0.5 million individuals. In this hospital, there are no geriatricians or geriatric care units. The aim of this study was to determine the prevalence of PIM use at admission and discharge among hospitalised elderly patients with acute medical illness. All consecutive patients aged 65 years or older who were admitted to the hospital for eight common disease categories (heart failure, pneumonia, ischaemic stroke, gastrointestinal bleeding, urinary tract infection (UTI), chronic obstructive pulmonary disease (COPD) or asthma, acute coronary syndrome and epilepsy) were included. As comorbidities can affect PIM use, ${ }^{4}$ the primary diagnosis for admission might also affect PIM use for hospitalised elderly patients. Therefore, patients were included according to their primary diagnosis for admission. Patients who died during their hospital stay or were transferred to the surgical ward or other hospitals within a few days after admission were excluded. Patients with a second admission due to the same disease during the study period were also excluded. Individual informed consent was not required because only data from medical records were used, and the patients were not contacted. The study protocol was approved and was carried out in accordance with the Declaration of Helsinki.

\section{Data collection and patient characteristics}

Data were collected using the electronic medical records of the National Hospital Organisation Tochigi Medical Centre. Information on age, gender, primary diagnosis for admission, social history, medical history, Charlson Comorbidity Index $(\mathrm{CCI})^{25}$ and medication use was retrieved from electronic medical records at the time of the patient's first admission. In this hospital, a comprehensive list of current medications is routinely compiled by pharmacists after admission. Medication management during hospitalisation was performed by the principal physician, who also determined and documented prescriptions at discharge. Therefore, information on medications at admission was retrieved from the comprehensive list compiled by pharmacists. Information on medications at discharge was based on the discharge prescriptions issued by principal physicians. The discharge prescriptions included all regular medications that were used at discharge. These included oral medications, inhalers and injections. As-needed medications for chronic disease were also included. However, eye drops, intranasal infusers, over-the-counter drugs and topical medications were excluded. Medications that were indicated for apparent transient disease were also excluded because one of the aims of this study was to evaluate the temporal change in the PIM prevalence from admission to discharge in terms of regularly prescribed medications. Furthermore, given that misdiagnosis is common in elderly patients ${ }^{2627}$ and that upper respiratory tract infection is often the trigger of heart failure, the inclusion of medications that were indicated for apparent transient disease overestimates the temporal reduction of PIM prevalence from admission to discharge. For example, antitussive medications for the common cold and antibiotic agents for a UTI and pneumonia were not included. Newly started medications were defined as medications that were not prescribed at admission but were prescribed at discharge.

\section{Outcome measures}

The primary outcome was the proportion of elderly patients with acute medical illness taking at least one PIM at admission and discharge. This outcome was also evaluated for subgroups of patients with the eight common medical illnesses mentioned above, classified according to their primary diagnosis at admission. PIMs were defined based on the 2015 Beers criteria of the American Geriatric Society. ${ }^{6}$ Two of the five components of the Beers criteria were used: PIM use in elderly adults and PIM use in elderly adults that is determined by drug-disease or drug-syndrome interactions that may exacerbate the disease or syndrome. These two parts were chosen because they have existed since the 1997 Beers criteria. ${ }^{28-30}$ In Japan, few methods for evaluating the appropriateness of medication use among elderly patients have been tested or validated. However, some studies have found that the Beers' criteria might be applicable in a Japanese setting, ${ }^{31}{ }^{32}$ and the Beers' criteria are the most frequently used criteria for this topic in Japanese research. Therefore, the Beers criteria were chosen. The number of PIMs according to drug subcategories was also evaluated.

Given that the 2015 Beers criteria targeted only the longterm use of proton pump inhibitors (PPIs), ${ }^{6}$ most PPIs that were newly started during hospitalisation, regardless of the appropriateness of their use, were not judged to be PIMs at discharge because the duration of hospital stay was often $\leq 8$ weeks. ${ }^{33}$ Moreover, the Beers criteria definition of high-risk patients for whom prophylactic use of PPIs is appropriate was ambiguous. Therefore, based on a previous study ${ }^{34}$ and the American College of Gastroenterology guidelines, ${ }^{35-37}$ PPI therapy was judged to be potentially inappropriate if the patients had none of the following indications: (1) peptic ulcer disease; (2) gastro-oesophageal reflux disease with or without oesophagitis; (3) Helicobacter pylori eradication therapy; (4) pathological hypersecretory conditions, such as Zollinger-Ellison syndrome; (5) use of non-steroidal anti-inflammatory drugs (NSAIDs); (6) use of antiplatelet therapy and at least one risk factor (history of peptic ulcer or concomitant use of anticoagulants or corticosteroids). 
Hospitalised patients aged 65 years or older $(n=2297)$

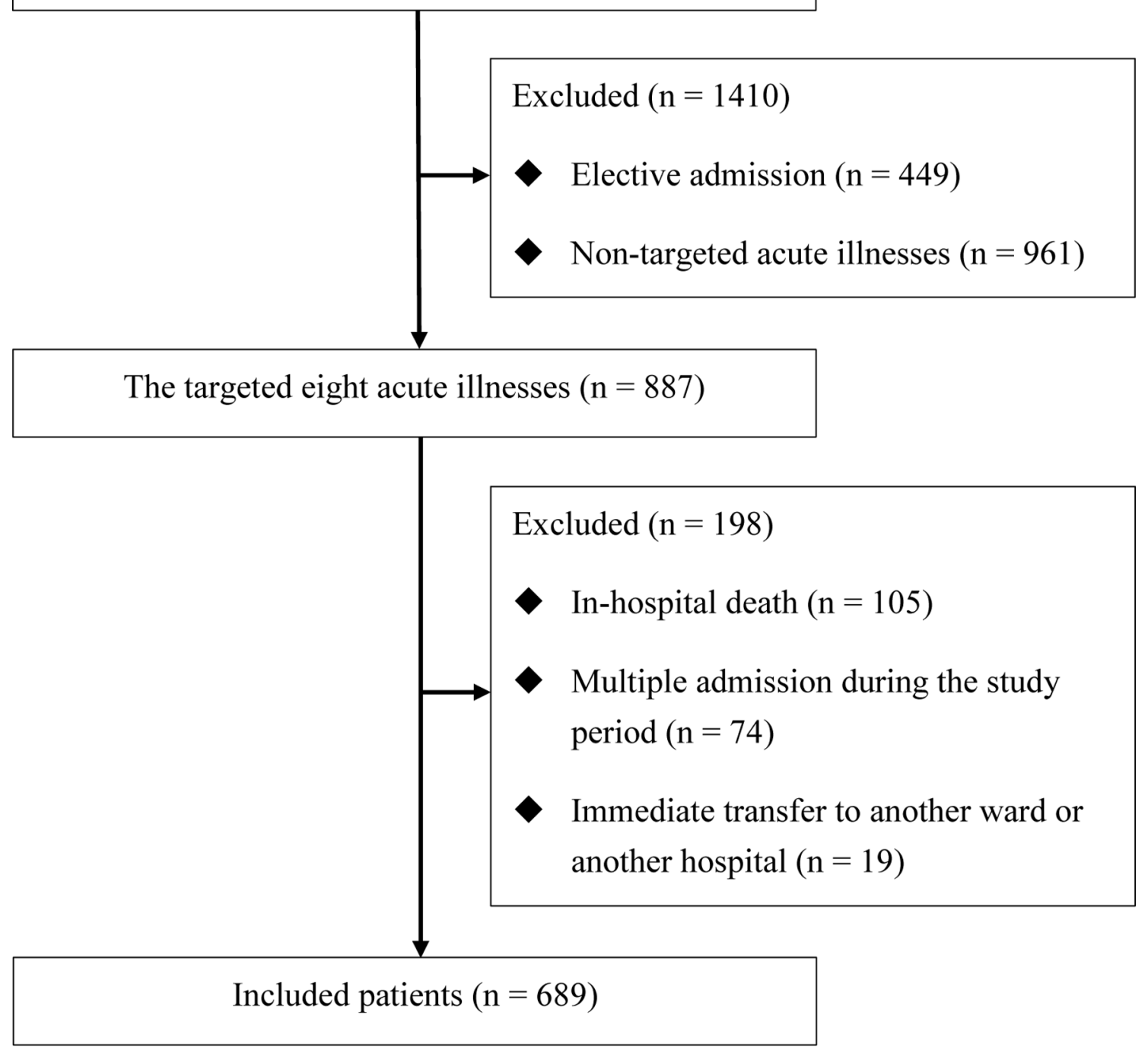

Figure 1 Flow chart of the 689 hospitalised elderly patients with the eight targeted acute medical illnesses.

\section{Statistical analysis}

A sample size calculation was not performed prior to data collection. Hospitalised patients were screened starting in September 2014 because this was when the hospital started using electronic medical records. Descriptive statistics were used to describe the study population. For the primary outcome, the proportion of patients taking any PIMs at admission and discharge among all patients was calculated. This proportion was also determined for subgroups of patients classified according to their primary diagnosis for admission. The $95 \%$ CIs were calculated for these outcomes. The number of all medications at admission was compared with the number of all medications at discharge using a two-tailed paired t-test. A comparison of the proportion of patients taking any PIMs at admission and at discharge was performed by using Fisher's exact test. The rates of reduction in the proportion of patients taking any PIMs from admission to discharge were also calculated. To identify the predictive factors of the use of any PIMs at discharge, a multivariate analysis using binary logistic regression was conducted to examine the associations between the use of any PIMs at discharge and selected variables. Based on previous studies, ${ }^{16202224}$ the following variables were entered in the logistic regression model: age, gender, CCI, number of total medications at admission and duration of hospital stay. These analyses were carried out using the Excel statistical software package V.2.11 (Bellcurve for Excel; Social Survey Research Information Co., Tokyo, Japan) or Stata V.15 (LightStone, Tokyo, Japan), and the level of significance was set at $5 \%$.

\section{Patient and public involvement statement}

No patients were involved in determining the research question or outcome measures nor were they involved in developing plans to design or implement the study. No patients were asked for advice during the interpretation or writing up of the results. There are no plans to 
Table 1 Total number of medications taken at admission, started during hospitalisation and prescribed at discharge among hospitalised elderly patients according to their primary diagnosis for admission

\begin{tabular}{lllll}
\hline & \multicolumn{2}{l}{ Number of medications, median (IQR) } \\
\cline { 2 - 5 } Primary diagnosis for admission & At admission & Newly started & At discharge & P values $\dagger$ \\
\hline Total, $\mathrm{n}=689$ & $5.0(3.0-8.0)$ & $1.0(0.0-2.0)$ & $4.0(2.0-5.0)$ & $<0.001$ \\
Heart failure, $\mathrm{n}=153$ & $6.0(3.0-8.0)$ & $2.0(1.0-3.0)$ & $5.0(3.0-6.0)$ & $<0.001$ \\
\hline Pneumonia, $\mathrm{n}=141$ & $5.0(3.0-7.0)$ & $0.0(0.0-1.0)$ & $3.0(1.0-5.0)$ & $<0.001$ \\
Ischaemic stroke, $\mathrm{n}=108$ & $5.0(2.5-7.0)$ & $1.0(1.0-2.0)$ & $3.0(1.0-5.0)$ & $<0.001$ \\
Gl bleeding, $\mathrm{n}=71$ & $5.0(3.0-7.0)$ & $1.0(0.0-2.0)$ & $2.0(1.0-4.0)$ & $<0.001$ \\
UTI, $\mathrm{n}=58$ & $5.0(2.0-7.0)$ & $0.0(0.0-1.0)$ & $2.0(1.0-4.0)$ & $<0.001$ \\
COPD or asthma, $\mathrm{n}=57$ & $7.0(5.0-9.0)$ & $1.0(0.0-2.0)$ & $5.0(3.0-7.0)$ & $<0.001$ \\
ACS, $\mathrm{n}=56$ & $4.5(1.5-7.0)$ & $4.0(3.0-6.0)$ & $6.0(5.0-8.0)$ & $<0.001$ \\
\hline Epilepsy, $\mathrm{n}=45$ & $5.0(3.0-8.0)$ & $1.0(0.0-2.0)$ & $2.0(1.0-4.0)$ & $<0.001$ \\
\hline
\end{tabular}

*Defined as medications that were not prescribed at admission but were prescribed at discharge.

†Comparison of the number of medications at admission and at discharge using a two-tailed paired t-test.

ACS, acute coronary syndrome; COPD, chronic obstructive pulmonary disease; GI, gastrointestinal; UTI, urinary tract infection.

disseminate the results of this research to study participants or the relevant patient community.

\section{RESULTS}

During the study period, 2297 patients aged 65 years or older were admitted. Out of 1848 admissions, after 449 elective admissions were excluded, 887 admissions were due to one of the eight targeted acute illnesses, 105 were excluded because of in-hospital death and 19 were excluded because of immediate transfer after admission to a surgical ward or another hospital. Additionally, 74 were excluded because of a second admission due to the same primary diagnosis during the study period. A total of 689 patients were thus included in the final analysis (figure 1). The primary diagnoses of these patients were heart failure $(n=153,22.2 \%)$, pneumonia $(\mathrm{n}=141,20.5 \%)$, ischaemic stroke $(\mathrm{n}=108,15.7 \%)$, gastrointestinal bleeding $(\mathrm{n}=71,10.3 \%)$, UTI $(\mathrm{n}=58$, $8.4 \%)$, COPD or asthma ( $\mathrm{n}=57,8.3 \%)$, acute coronary syndrome $(\mathrm{n}=56,8.1 \%)$ and epilepsy $(\mathrm{n}=45,6.5 \%)$.

The baseline characteristics of the patients are presented in online supplementary table S1. Of the 689 patients, the median age was 82.0 years (IQR 76.0-88.0), $348(50.5 \%)$ were men, the median CCI was 2.0 (IQR $1.0-3.0), 168(24.4 \%)$ had dementia and $94(13.6 \%)$ were institutional residents. The median duration of hospital stay was 16.0 days (IQR 10.0-29.0).

Table 1 shows the number of medications at admission, the number newly started during hospitalisation and the number at discharge among the hospitalised elderly patients according to their primary diagnosis for admission. The median number of medications taken

Table 2 The temporal change in the proportion of hospitalised elderly patients taking any PIMs from admission to discharge according to their primary diagnosis for admission. Values are given as numbers (percentages) unless stated otherwise

\begin{tabular}{|c|c|c|c|c|}
\hline \multirow{2}{*}{$\begin{array}{l}\text { Primary diagnosis for } \\
\text { admission }\end{array}$} & \multicolumn{4}{|c|}{ Proportion of patients taking any PIMs* } \\
\hline & At admission & At discharge & Reduction rate $(95 \% \mathrm{Cl})$ & P values \\
\hline Total, $n=689$ & $330(47.9)$ & $173(25.1)$ & $0.48(0.41$ to 0.53$)$ & $<0.001$ \\
\hline Pneumonia, $n=141$ & $75(53.2)$ & $33(23.4)$ & $0.56(0.43$ to 0.66$)$ & $<0.001$ \\
\hline Ischaemic stroke, $n=108$ & $43(40.0)$ & $27(25.0)$ & $0.37(0.12$ to 0.55$)$ & 0.001 \\
\hline UTI, $n=58$ & $28(48.3)$ & $13(22.4)$ & 0.54 (0.29 to 0.70$)$ & $<0.001$ \\
\hline COPD or asthma, $n=57$ & $31(54.4)$ & $20(35.1)$ & 0.35 (0.14 to 0.51$)$ & $<0.001$ \\
\hline ACS, $n=56$ & $23(41.1)$ & 10 (17.9) & $0.57(0.28$ to 0.74$)$ & $<0.001$ \\
\hline Epilepsy, $n=45$ & $21(46.7)$ & $9(20.0)$ & 0.57 (0.30 to 0.74$)$ & $<0.001$ \\
\hline
\end{tabular}

*PIMs were defined based on the 2015 American Geriatric Society Beers Criteria.

†Comparison of the numbers at admission and at discharge using Fisher's exact test.

ACS, acute coronary syndrome; COPD, chronic obstructive pulmonary disease; GI, gastrointestinal; PIM, potentially inappropriate medication; UTI, urinary tract infection. 
Table 3 Summary of the multivariate logistic regression results* for predicting the use of any PIMs $†$ at discharge

\begin{tabular}{|c|c|c|}
\hline Variables & OR (95\% Cl) & $P$ values \\
\hline Age & 0.97 (0.96 to 0.97) & 0.02 \\
\hline Women & 1.70 (1.17 to 2.48$)$ & 0.01 \\
\hline Charlson Comorbidity Index & 1.03 (0.92 to 1.16$)$ & 0.56 \\
\hline $\begin{array}{l}\text { Number of medications at } \\
\text { admission }\end{array}$ & 1.20 (1.14 to 1.27$)$ & $<0.001$ \\
\hline Duration of hospital stay & 1.00 (1.01 to 1.00$)$ & 0.96 \\
\hline
\end{tabular}

*The following variables were used: age, gender, Charlson Comorbidity Index, number of medications at admission and duration of hospital stay.

†PIMs were defined based on the 2015 American Geriatric Society Beers Criteria.

PIM, potentially inappropriate medication.

by all patients was significantly lower at discharge than at admission (4.0 (IQR 2.0-5.0) and 5.0 (IQR 3.0-8.0), respectively; $\mathrm{p}<0.001)$, although a median of 1.0 new medications (IQR 0.0-2.0) were started during hospital stays. All the subgroups of patients classified by primary diagnosis for admission, except those admitted for an acute coronary syndrome, showed similar temporal changes in the median number of medications from admission to discharge. Table 2 shows the proportion of patients taking any PIMs at admission and at discharge according to their primary diagnosis for admission. The proportion of patients taking any PIMs at admission was $47.9 \%$ (95\% CI $44.2 \%$ to $51.6 \%$ ), while the proportion of patients taking any PIMs at discharge was $25.1 \%$ (95\% CI $21.9 \%$ to $28.4 \%$ ). The proportion of patients taking any PIMs was significantly lower at discharge than at admission (reduction rate $0.48,95 \%$ CI 0.41 to 0.53 ). The subgroups classified by primary diagnosis for admission showed similar changes in the proportion of PIM use from admission to discharge. In the multivariate analysis using binary logistic regression, younger age, female gender and increasing number of medications at admission were independently associated with a higher risk of the use of any PIMs at discharge (table 3). However, CCI and duration of hospital stay were not statistically significant predictive factors for the use of any PIMs at discharge.

Table 4 shows the number of PIMs according to drug subcategories at admission and discharge. Of all medications that were PIMs at admission, $341(66.9 \%)$ were discontinued during hospitalisation or were not PIMs at discharge (online supplementary table S2). The most common PIMs used at admission and discharge were benzodiazepines, PPIs and non-benzodiazepine

Table 4 Total number of PIMs* according to the subcategories of drugs taken at admission, newly started during hospitalisation and taken at discharge

\begin{tabular}{|c|c|c|c|c|}
\hline Drug category & At admission & Newly started $\dagger$ & At discharge & $P$ values $\ddagger$ \\
\hline Total & $510(100.0)$ & $50(100.0)$ & 219 (100.0) & $<0.001$ \\
\hline Benzodiazepines & $141(27.6)$ & 7 (14.0) & $65(29.7)$ & $<0.001$ \\
\hline Proton pump inhibitors§ & $129(25.3)$ & $23(46.0)$ & $83(37.9)$ & $<0.001$ \\
\hline Hypnotics (non-benzodiazepines) & $38(7.5)$ & $5(10.0)$ & $21(9.6)$ & 0.001 \\
\hline Antipsychotics & $36(7.1)$ & $1(2.0)$ & $15(6.8)$ & $<0.001$ \\
\hline NSAIDs & $28(5.5)$ & $0(0.0)$ & $0(0.0)$ & $<0.001$ \\
\hline Ticlopidine or dipyridamole & $18(3.5)$ & $0(0.0)$ & $1(0.5)$ & $<0.001$ \\
\hline Peripheral alpha- 1 blocker & $18(3.5)$ & $7(14.0)$ & $12(5.5)$ & 0.16 \\
\hline Digoxin & $16(3.1)$ & $1(2.0)$ & $2(0.9)$ & $<0.001$ \\
\hline $\mathrm{H}_{2}$-receptor antagonists for dementia & $14(2.7)$ & $0(0.0)$ & $3(1.4)$ & $<0.001$ \\
\hline Anticholinergics & $14(2.7)$ & $0(0.0)$ & $3(1.4)$ & 0.002 \\
\hline First-generation antihistamines & $12(2.4)$ & $1(2.0)$ & $1(0.5)$ & 0.004 \\
\hline Antidepressants & $11(2.2)$ & $1(2.0)$ & $4(1.8)$ & 0.05 \\
\hline Verapamil or diltiazem for heart failure & $10(2.0)$ & $1(2.0)$ & $4(1.8)$ & 0.06 \\
\hline Others & $25(4.9)$ & $2(4.0)$ & $4(1.8)$ & $<0.001$ \\
\hline
\end{tabular}

Values are given as numbers (percentages).

*PIMs are defined based on the 2015 American Geriatric Society Beers Criteria.

†Defined as medications that were not prescribed at admission but were prescribed at discharge.

$\ddagger$ Comparison of the number of PIMs at admission and at discharge using a two-tailed paired t-test.

§PPI therapy was judged to be potentially inappropriate if the patients had none of the following indications: (1) peptic ulcer disease; (2)

GERD with or without oesophagitis; (3) Helicobacter pylori eradication therapy; (4) pathological hypersecretory conditions, such as Zollinger-

Ellison syndrome; (5) use of NSAIDs; (6) use of antiplatelet therapy and at least one risk factor (history of peptic ulcer or concomitant use of anticoagulants or corticosteroids).

GERD, gastro-oesophageal reflux disease; NSAIDs, non-steroidal anti-inflammatory drugs; PIM, potentially inappropriate medication; PPI, proton pump inhibitor. 
hypnotics. These three categories comprised more than $60 \%$ of the total PIMs at admission and discharge.

\section{DISCUSSION}

The results of this study show that the proportion of patients taking at least one PIM at admission among hospitalised elderly patients with acute medical illness was $47.9 \%$. Regardless of the primary diagnosis for admission, more than two-fifths of the patients took at least one PIM at admission. Furthermore, approximately one-fourth of all patients took at least one PIM at discharge, although the proportion of patients taking at least one PIM decreased significantly from admission to discharge.

To the knowledge of the author, this is the first study to determine the prevalence of PIM use at admission and discharge among hospitalised elderly patients with acute medical illness in Japan. Although one Japanese multicentre prospective study reported the frequency of PIM prescription during hospitalisation, this study did not aim to investigate the temporal change in PIM prevalence from admission to discharge ${ }^{38}$ Therefore, it is unclear whether the proportion of PIM use at admission and discharge among the population in the present study is higher or lower than in other hospitals in Japan due to the lack of comparable studies. However, the prevalence of PIM use among elderly patients at admission and discharge in this study is consistent with that of studies conducted in other countries, ${ }^{12}{ }^{15-24}$ although the prevalence of PIM use at admission and discharge among elderly patients with acute coronary syndrome in this study was much higher than that of hospitalised elderly patients with acute myocardial infarction in the USA. ${ }^{14}$ Given the harmful effects of PIMs for elderly patients, ${ }^{9}{ }^{10}$ further studies are warranted to confirm these findings in other hospitals in Japan.

Although approximately one-fourth of all patients were taking at least one PIM at discharge, this study shows that there was a significant reduction in the proportion of PIM use from admission to discharge among hospitalised elderly patients with acute medical illness, which is an encouraging finding. This finding is also consistent with that of past studies showing a significant reduction in the proportion of PIM use from admission to discharge among similar patient populations, ${ }^{19-24}$ although some studies reported that the proportion of PIM use did not change or increase from admission to discharge. ${ }^{14-18}$ However, this finding of the present study should be interpreted with caution because most internal medicine physicians who care for hospitalised patients at this hospital make efforts to avoid PIM and polypharmacy for elderly patients in routine practice. ${ }^{39}$ For example, NSAIDs and antipsychotics are rarely introduced for hospitalised elderly patients in the medical ward of this hospital, as table 4 shows. Therefore, it is unclear whether similar reductions in the proportion of PIM use from admission to discharge among hospitalised elderly patients with acute medical illness occur in other hospitals in Japan. Considering the unexplained regional variations in the use of PIMs among elderly patients during hospitalisation, ${ }^{14} 40$ these findings need to be confirmed in other Japanese hospitals.

In this study, CCI and duration of hospital stay were not statistically significant predictive factors for the use of any PIMs at discharge. These findings are consistent with those of past studies. ${ }^{20}{ }^{22}$ Younger age, female gender and increasing number of medications at admission were independently associated with a higher risk of the use of any PIMs at discharge in this study. However, past studies have found mixed results regarding the associations among age, gender and number of medications at admission and the use of any PIMs at discharge. ${ }^{16202224}$ Therefore, further studies are needed to evaluate the effect of these factors on the use of any PIM use at discharge among hospitalised elderly patients with acute medical illness.

\section{Limitations}

These results presented here should be interpreted in the context of several limitations. First, this study used a retrospective design, which might have generated biased data. Second, hospitalised patients who died or were transferred to other settings were excluded, as were patients with acute medical illnesses other than the eight illnesses considered in this study. Given that patients who die during hospitalisation are often older and have a higher burden of comorbidities, the exclusion of these patients might underestimate the prevalence of PIM use at admission. Third, the prevalence of PIM use after discharge was not evaluated. Given that a significant increase in the long-term prevalence of PIM use has been observed among elderly patients who have undergone interventions regarding polypharmacy to reduce PIM use, ${ }^{41}$ it remains uncertain whether the reduction in PIM use observed in our study is sustainable over the long term. Therefore, the extent of the reduction of PIM prevalence from admission to discharge observed in the present study might be overestimated. Fourth, this study was limited to a single centre and to elderly patients admitted for eight categories of acute medical illnesses, and therefore, the results cannot be easily generalised. These findings should be confirmed for other acute illnesses and in other hospitals in Japan. Fifth, the length of hospitalisation is relatively longer in Japan than in other countries, ${ }^{42}$ which limits the generalisability of these findings to other countries. However, the multivariate analysis conducted in the present study found no association between PIM use at discharge and the duration of hospital stay. Sixth, drugs classified as PIMs are not necessarily inappropriate. ${ }^{5}$ Furthermore, it is unknown whether reducing PIM use improves clinically important patient outcomes. ${ }^{43-45}$ Seventh, this study used the alternative definition for the potentially inappropriate use of PPIs. Given that this definition 
targets both short-term and long-term use, unlike the Beers criteria, the prevalence of the potentially inappropriate use of PPIs might have been overestimated. However, prescriptions for PPIs in elderly patients are often long term ( $>8$ weeks), ${ }^{46} 47$ and PPIs that are newly started during hospitalisation are often continued after discharge. ${ }^{48}$ Finally, our assessment did not include potential prescription omissions ${ }^{7}$ or other clinically important outcomes, such as mortality and adverse drug events.

\section{Implications for clinical practice}

The prevalence of PIM use at admission in hospitalised elderly patients with acute medical illness was high in Japan, as it is in other countries. Furthermore, the prevalence of PIM use was still high at discharge, even though hospitalisation due to medical illness can provide a good opportunity to review medications and discontinue inappropriate ones. ${ }^{49}$ Given the harmful effects of PIMs for elderly patients, ${ }^{9}{ }^{10}$ further studies are needed to develop an approach for minimising PIM use in the inpatient setting. ${ }^{14}$

\section{CONCLUSIONS}

A substantial proportion of hospitalised elderly patients with acute medical illness in the present study took PIMs at admission and discharge. Given the harmful effects of PIMs on elderly patients, these findings should be confirmed at other hospitals in Japan.

Acknowledgements I thank Rei Kutsuzawa for help in collecting data for the targeted patients from the database. I also thank the reviewers and editors for providing many valuable comments to improve the quality of this manuscript when previous versions of this manuscript were rejected by Geriatrics \& Gerontology International and BMC Geriatrics. I also thank the BMJ Open reviewers for their helpful comments.

Contributors I conceived and designed this study, collected and analysed the data, wrote the main paper and read and approved the final manuscript.

Funding This research received no specific grant from any funding agency in the public, commercial or not-for-profit sectors.

Competing interests None declared.

Patient consent Not required.

Ethics approval This study was approved by the Medical Ethical Committee of the National Hospital Organisation Tochigi Medical Centre (No. 28-21). This study was conducted in accordance with the Ethical Guidelines for Epidemiological Research in Japan.

Provenance and peer review Not commissioned; externally peer reviewed.

Data sharing statement Data sharing is not applicable because informed consent for data sharing was not received from the participants.

Open access This is an open access article distributed in accordance with the Creative Commons Attribution Non Commercial (CC BY-NC 4.0) license, which permits others to distribute, remix, adapt, build upon this work non-commercially, and license their derivative works on different terms, provided the original work is properly cited, appropriate credit is given, any changes made indicated, and the use is non-commercial. See: http://creativecommons.org/licenses/by-nc/4.0/.

\section{REFERENCES}

1. Wolff JL, Starfield B, Anderson G. Prevalence, expenditures, and complications of multiple chronic conditions in the elderly. Arch Intern Med 2002;162:2269-76.
2. Kaufman DW, Kelly JP, Rosenberg L, et al. Recent patterns of medication use in the ambulatory adult population of the United States: the Slone survey. JAMA 2002;287:337-44.

3. Steinman MA, Landefeld CS, Rosenthal GE, et al. Polypharmacy and prescribing quality in older people. J Am Geriatr Soc 2006;54:1516-23.

4. Tommelein E, Mehuys E, Petrovic M, et al. Potentially inappropriate prescribing in community-dwelling older people across Europe: a systematic literature review. Eur J Clin Pharmacol 2015;71:1415-27.

5. Steinman MA, Beizer JL, DuBeau CE, et al. How to use the American Geriatrics Society 2015 Beers Criteria-A Guide for Patients, Clinicians, Health Systems, and Payors. J Am Geriatr Soc 2015;63:e1-e7.

6. By the American Geriatrics Society 2015 Beers Criteria Update Expert Panel. American Geriatrics Society 2015 Updated Beers Criteria for Potentially Inappropriate Medication Use in Older Adults. $J$ Am Geriatr Soc 2015;63:2227-46.

7. O'Mahony D, O'Sullivan D, Byrne S, et al. STOPP/START criteria for potentially inappropriate prescribing in older people: version 2. Age Ageing 2015;44:213-8.

8. Kojima T, Mizukami K, Tomita N, et al. Screening Tool for Older Persons' Appropriate Prescriptions for Japanese: Report of the Japan Geriatrics Society Working Group on "Guidelines for medical treatment and its safety in the elderly". Geriatr Gerontol Int 2016;16:983-1001.

9. Lau DT, Kasper JD, Potter DE, et al. Hospitalization and death associated with potentially inappropriate medication prescriptions among elderly nursing home residents. Arch Intern Med 2005;165:68-74.

10. Stockl KM, Le L, Zhang S, et al. Clinical and economic outcomes associated with potentially inappropriate prescribing in the elderly. Am J Manag Care 2010;16:e1-e10.

11. Opondo D, Eslami S, Visscher S, et al. Inappropriateness of medication prescriptions to elderly patients in the primary care setting: a systematic review. PLoS One 2012;7:e43617.

12. Gallagher P, Lang PO, Cherubini A, et al. Prevalence of potentially inappropriate prescribing in an acutely ill population of older patients admitted to six European hospitals. Eur J Clin Pharmacol 2011;67:1175-88.

13. Hustey FM, Wallis N, Miller J. Inappropriate prescribing in an older ED population. Am J Emerg Med 2007;25:804-7.

14. Lund BC, Schroeder MC, Middendorff G, et al. Effect of hospitalization on inappropriate prescribing in elderly Medicare beneficiaries. J Am Geriatr Soc 2015;63:699-707.

15. Morandi A, Vasilevskis EE, Pandharipande PP, et al. Inappropriate medications in elderly ICU survivors: where to intervene? Arch Intern Med 2011;171:1032-4.

16. Frankenthal $D$, Lerman $Y$, Lerman $Y$. The impact of hospitalization on potentially inappropriate prescribing in an acute medical geriatric division. Int J Clin Pharm 2015;37:60-7.

17. Bakken MS, Ranhoff $\mathrm{AH}$, Engeland $\mathrm{A}$, et al. Inappropriate prescribing for older people admitted to an intermediate-care nursing home unit and hospital wards. Scand J Prim Health Care 2012;30:169-75.

18. Mansur N, Weiss A, Beloosesky Y. Is there an association between inappropriate prescription drug use and adherence in discharged elderly patients? Ann Pharmacother 2009;43:177-84.

19. Saltvedt I, Spigset O, Ruths S, et al. Patterns of drug prescription in a geriatric evaluation and management unit as compared with the general medical wards: a randomised study. Eur J Clin Pharmacol 2005;61:921-8.

20. Laroche ML, Charmes JP, Nouaille Y, et al. Impact of hospitalisation in an acute medical geriatric unit on potentially inappropriate medication use. Drugs Aging 2006;23:49-59.

21. Chan VT, Woo BK, Sewell DD, et al. Reduction of suboptimal prescribing and clinical outcome for dementia patients in a senior behavioral health inpatient unit. Int Psychogeriatr 2009;21:195-9.

22. Lang PO, Vogt-Ferrier N, Hasso $\mathrm{Y}$, et al. Interdisciplinary geriatric and psychiatric care reduces potentially inappropriate prescribing in the hospital: interventional study in 150 acutely ill elderly patients with mental and somatic comorbid conditions. J Am Med Dir Assoc 2012;13:406.e1-e7.

23. Egger SS, Bachmann A, Hubmann N, et al. Prevalence of potentially inappropriate medication use in elderly patients: comparison between general medical and geriatric wards. Drugs Aging 2006;23:823-37.

24. Onatade R, Auyeung V, Scutt G, et al. Potentially inappropriate prescribing in patients on admission and discharge from an older peoples' unit of an acute UK hospital. Drugs Aging 2013;30:729-37. 
25. Charlson ME, Pompei P, Ales KL, et al. A new method of classifying prognostic comorbidity in longitudinal studies: development and validation. J Chronic Dis 1987;40:373-83.

26. Singh H, Giardina TD, Meyer AN, et al. Types and origins of diagnostic errors in primary care settings. JAMA Intern Med 2013;173:418-25.

27. Skinner TR, Scott IA, Martin JH. Diagnostic errors in older patients: a systematic review of incidence and potential causes in seven prevalent diseases. Int J Gen Med 2016;9:137-46.

28. Beers $\mathrm{MH}$. Explicit criteria for determining potentially inappropriate medication use by the elderly. An update. Arch Intern Med 1997;157:1531-6.

29. Fick DM, Cooper JW, Wade WE, et al. Updating the Beers criteria for potentially inappropriate medication use in older adults: results of a US consensus panel of experts. Arch Intern Med 2003;163:2716-24.

30. American Geriatrics Society 2012 Beers Criteria Update Expert Panel. American Geriatrics Society updated Beers Criteria for potentially inappropriate medication use in older adults. J Am Geriatr Soc 2012;60:616-31.

31. Niwata S, Yamada Y, Ikegami N. Prevalence of inappropriate medication using Beers criteria in Japanese long-term care facilities. BMC Geriatr 2006;6:1.

32. Akazawa M, Imai H, Igarashi A, et al. Potentially inappropriate medication use in elderly Japanese patients. Am J Geriatr Pharmacother 2010;8:146-60.

33. Zhang X, Zhou S, Pan K, et al. Potentially inappropriate medications in hospitalized older patients: a cross-sectional study using the Beers 2015 criteria versus the 2012 criteria. Clin Interv Aging 2017;12:1697-703.

34. Bergamo D, Pastorino A, Greppi F, et al. Inappropriate Proton Pump Inhibitor Prescription in Elderly Adults: As Usual As Dangerous. J Am Geriatr Soc 2015;63:2198-9.

35. Bhatt DL, Scheiman J, Abraham NS, et al. ACCF/ACG/AHA 2008 expert consensus document on reducing the gastrointestinal risks of antiplatelet therapy and NSAID use. Am J Gastroenterol 2008;103:2890-907.

36. Lanza FL, Chan FKL, Quigley EMM. Practice Parameters Committee of the American College of Gastroenterology. Guidelines for prevention of NSAID-related ulcer complications. Am J Gastroenterol 2009;104:728-38.

37. Abraham NS, Hlatky MA, Antman EM, et al. ACCF/ACG/AHA 2010 expert consensus document on the concomitant use of proton pump inhibitors and thienopyridines: a focused update of the ACCF/ ACG/AHA 2008 expert consensus document on reducing the gastrointestinal risks of antiplatelet therapy and NSAID use. Am J Gastroenterol 2010;105:2533-49.
38. Sakuma M, Morimoto T, Matsui K, et al. Epidemiology of potentially inappropriate medication use in elderly patients in Japanese acute care hospitals. Pharmacoepidemiol Drug Saf 2011;20:386-92.

39. Komagamine J, Hagane K. Intervention to improve the appropriate use of polypharmacy for older patients with hip fractures: an observational study. BMC Geriatr 2017;17:288.

40. Rothberg MB, Pekow PS, Liu F, et al. Potentially inappropriate medication use in hospitalized elders. J Hosp Med 2008;3:91-102.

41. Frankenthal D, Israeli A, Caraco $Y$, et al. Long-term outcomes of medication intervention using the screening tool of older persons potentially inappropriate prescriptions screening tool to alert doctors to right treatment criteria. J Am Geriatr Soc 2017;65:e33-8.

42. Tiessen J, Kambara H, Sakai T, et al. What causes international variations in length of stay: a comparative analysis for two inpatient conditions in Japanese and Canadian hospitals. Health Serv Manage Res 2013;26:86-94.

43. Pasina L, Djade CD, Tettamanti M, et al. Prevalence of potentially inappropriate medications and risk of adverse clinical outcomes in a cohort of hospitalized elderly patients: results from the REPOSI study. J Clin Pharm Ther 2014;39:511-5.

44. Hill-Taylor B, Walsh KA, Stewart S, et al. Effectiveness of the STOPP/START (Screening Tool of Older Persons' potentially inappropriate Prescriptions/Screening Tool to Alert doctors to the Right Treatment) criteria: systematic review and metaanalysis of randomized controlled studies. J Clin Pharm Ther 2016;41:158-69.

45. Clyne B, Fitzgerald C, Quinlan A, et al. Interventions to Address Potentially Inappropriate Prescribing in Community-Dwelling Older Adults: A Systematic Review of Randomized Controlled Trials. J Am Geriatr Soc 2016;64:1210-22.

46. Moriarty F, Bennett K, Cahir C, et al. Characterizing potentially inappropriate prescribing of proton pump inhibitors in older people in primary care in Ireland from 1997 to 2012. J Am Geriatr Soc 2016;64:e291-6.

47. Wallerstedt SM, Fastbom J, Linke J, et al. Long-term use of proton pump inhibitors and prevalence of disease- and drug-related reasons for gastroprotection-a cross-sectional population-based study. Pharmacoepidemiol Drug Saf 2017;26:9-16.

48. Villamañán $\mathrm{E}$, Ruano $\mathrm{M}$, Lara $\mathrm{C}$, et al. Reasons for initiation of proton pump inhibitor therapy for hospitalised patients and its impact on outpatient prescription in primary care. Rev Esp Enferm Dig 2015;107:652-8.

49. Jansen J, Naganathan V, Carter SM, et al. Too much medicine in older people? Deprescribing through shared decision making. BMJ 2016;353:i2893. 